\title{
PEMBUATAN MEMBRAN SELULOSA ASETAT TERMODIFIKASI ZEOLIT ALAM LAMPUNG UNTUK PEMISAHAN ETANOL-AIR SECARA PERVAPORASI
}

\section{Evy Ernawati}

Jurusan Kimia, Fakultas Matematika dan Ilmu Pengetahuan Alam,Universitas Padjadjaran Jl. Raya Bandung-Sumedang km.21 Jatinangor, Sumedang 45363, Jawa Barat - Indonesia e-mail: evyerna_p@yahoo.com

\begin{abstract}
Abstrak: Selulosa asetat merupakan salah satu jenis polimer yang paling banyak digunakan dalam industri. Salah satu kegunaan selulosa asetat adalah sebagai bahan membran, namun membran ini memiliki beberapa kelemahan antara lain derajat penggembungannya tinggi, sensitif terhadap perubahan suhu dan ketahanan terhadap asam. Pemberian mineral ke dalam bahan membran, dapat memberikan peluang untuk pengembangan material mineral-polimer yang digunakan pada proses pemisahan, yaitu dapat meningkatkan kekuatan mekanik, ketahanan terhadap panas, fluks dan selektivitas. Tujuan dari penelitian ini adalah membuat membran selulosa asetat dengan penambahan zeolit alam lampung dan mengevaluasi kinerja membran terhadap pemisahan campuran etanol-air dengan metode pervaporasi. Pembuatan membran selulosa asetat dilakukan dengan teknik inversi fase, yaitu dengan mengunakan metode penguapan pelarut. Proses pervaporasi dilakukan pada suhu $40^{\circ} \mathrm{C}$ dan konsentrasi permeat yang dihasilkan ditentukan dengan menggunakan refraktometer. Karakterisasi membran meliputi pengukuran fluks dan selektivitas. Hasil pervaporasi menunjukkan bahwa membran selulosa asetat $20 \%$ tanpa modifikasi memiliki nilai selektivitas 6,16 dan fluks $771,0 \mathrm{~g} / \mathrm{m}^{2} \mathrm{jam}$. Membran selulosa asetat $20 \%$ termodifikasi zeolit alam 5\% selektivitas meningkat menjadi 22,30 sementara fluks sedikit menurun menjadi 680,9 g/m $\mathrm{m}^{2} \mathrm{jam}$.
\end{abstract}

\section{Kata kunci: Membran Selulosa Asetat, Zeolit Alam Lampung, Pervaporasi}

\begin{abstract}
Cellulose acetate is one of polymers mostly used in industry. One of the uses of this polymer is for a membrane material. Unfortunately, this membrane has some weaknesses, which include a high swelling degree, sensitive to temperature, and resistance to acidity. Incorporation of minerals into a membrane could give a possibility to develop mineral-polymer materials used in separation processes. The incorporation can increase the mechanical strength, the heat resistancy, the flux, and the selectivity of the resulted membranes. The aim of this research was to prepare cellulose acetate with added natural zeolite of Lampung origin and to evaluate the performance of the resulted membrane in the separation of ethanol-water mixtures using the pervaporation method. Preparation of the celulose acetate membrane was conducted using the phase-inversion technique, i.e. the method of solvent evaporation. The pervaporation process was carried out at $40^{\circ} \mathrm{C}$ and the concentration of the resulted permeates was measured using a refractometer. Characterization of the membrane consisted of selectivity and flux measurements. The result of the pervaporation process showed that $20 \%$ cellulose acetate without any modification had a selectivity of 6.16 and a flux of $771.0 \mathrm{~g} / \mathrm{m}^{2}$ hour. Meanwhile, the modification of $20 \%$ cellulose acetate with $5 \%$ natural zeolite had increased the selectivity to 22.30, but decreased in flux to $680.9 \mathrm{~g} / \mathrm{m}^{2}$ hour.
\end{abstract}

\section{Keywords: Cellulose Acetate Membrane, Nature Zeolite of Lampung, Pervaporation}

\section{PENDAHULUAN}

Etanol dengan kemurnian tinggi dapat digunakan sebagai aditif dari bahan bakar. Untuk memperoleh etanol dengan kemurnian tinggi, biasanya digunakan proses distilasi. Namun proses ini hanya mampu menghasilkan etanol dengan kemurnian tidak lebih dari 95,6\%. Pada konsentrasi tersebut terbentuk azeotrop sehingga pada proses distilasi tidak mampu menghasilkan etanol dengan konsentrasi lebih tinggi lagi. Teknik pervaporasi merupakan suatu alternatif yang dapat digunakan untuk pemisahan campuran azeotrop. Selain itu teknik ini sangat efektif dan efisien terhadap penggunaan energi (Groot et al., 1992 \& Wang et al., 2009). Penggunaan jenis membran untuk proses pervaporasi harus sesuai dengan sifat membran, jenis pelarut, dan senyawa yang dipisahkan (Ma et al.,
2007). Pemisahan etanol-air secara pervaporasi harus menggunakan polimer pembuat membran yang hidrofilik. Kataoka et al. (1991) telah menggunakan membran selulosa asetat untuk pemisahan etanol-air. Membran ini dapat digunakan untuk pemisahan dengan fluks yang tinggi tetapi selektivitasnya rendah. Hal ini disebabkan karena membran selulosa asetat mempunyai gugus hidroksil yang dapat mengabsorpsi molekul-molekul air sehingga membran mudah menggembung (swelling) dalam larutan (Kariduraganavar et al., 2004 \& Kittur et al., 2003).

Dengan penambahan mineral ke dalam suatu sistem membran dapat mengubah kekuatan mekanik, fisik, memperbaiki struktur membran, serta berpeluang untuk pengembangan material kompleks mineral-polimer yang digunakan sebagai membran untuk proses pemisahan (Goossens \& Van Haute, 
1976). Disamping itu beberapa peneliti (Bowen et al., 2004 \& Okumus et al., 2003), menyatakan bahwa zeolit yang ditambahkan sebagai bahan pengisi pada matriks membran dapat meningkatkan kinerja membran melalui proses pervaporasi.

Pada penelitian ini dilakukan modifikasi selulosa asetat dengan zeolit untuk memperbaiki dan meningkatkan kinerja membran khususnya meningkatkan fluks dan selektivitas. Zeolit yang digunakan adalah zeolit alam karena memberikan banyak keuntungan yaitu relatif murah dan ketersediaannya melimpah.

Pada penelitian ini menggunakan zeolit alam lampung sebagai bahan pengisi membran selulosa asetat, selanjutnya diaplikasikan untuk proses pemisahan etanol-air menggunakan teknik pervaporasi

\section{BAHAN DAN METODE}

Bahan. Polimer selulosa (CA) asetat dari Aldrich dengan kadar asetil 39,8\%, pelarut aseton, zeolit alam (asal Lampung) 230 mesh, nitrogen cair, etanol.

Metode. Metode yang digunakan dalam penelitian ini adalah menggunakan metode eksperimen skala laboratorium. Proses pembuatan membran dilakukan melalui teknik inversi fase dengan metode penguapan pelarut. Membran yang dibuat ada dua macam, yaitu membran selulosa asetat dan membran selulosa asetat yang dimodifikasi zeolit alam (asal Lampung). Kinerja masing-masing membran diamati meliputi fluks dan selektivitas berdasarkan teknik pervaporasi.

Aktivasi zeolit. Zeolit dicuci dan dikeringkan dalam oven $\left(110^{\circ} \mathrm{C}\right)$ selama 4 jam. Selanjutnya zeolit dihaluskan dan diayak hingga diperoleh ukuran 230 mesh dan dipanaskan di dalam tanur dengan suhu $400^{\circ} \mathrm{C}$ selama 2 jam. Kemudian zeolit disimpan dalam desikator (Husaini, 1991).

Pembuatan Membran. Pada pembuatan membran selulosa asetat, polimer selulosa asetat $20 \% \mathrm{w} / \mathrm{w}$ dilarutkan dalam aseton selama 24 jam. Selanjutnya larutan disimpan dalam lemari es untuk proses debubbling (penghilangan gelembung) selama 24 jam kemudian dicetak di atas plat kaca. Selanjutnya dilakukan penguapan pelarut yaitu membran tersebut letakkan dalam desikator selama tujuh hari. Pada pembuatan membran selulosa asetat yang dimodifikasi zeolit alam, polimer selulosa asetat $20 \%$ w/w dilarutkan dalam aseton. Kemudian zeolit alam dimasukkan dalam larutan membran tersebut sambil diaduk selama 24 jam. Selanjutnya hal yang sama dilakukan seperti di atas. Zeolit alam yang digunakan bervariasi konsentrasinya yaitu 5-20\% b/b SA.

Pervaporasi. Membran diletakkan di atas pendukung secara horizontal pada rancangan alat pervaporasi (Gambar 1). Ke dalam labu dimasukkan 100g umpan etanol dan dipanaskan sampai $40^{\circ} \mathrm{C}$. Proses pervaporasi dilakukan pada tekanan vakum $(0,5$ mBar). Sebelum dan sesudah proses pervaporasi, larutan umpan diambil sedikit dan setiap 1 jam sekali permeat yang dihasilkan diambil. Pengambilan permeat dilakukan sebanyak 4 kali. Larutan umpan dan permeat dianalisis lebih lanjut menggunakan refraktometer.

Kinerja pemisahan dari pervaporasi ditentukan oleh nilai fluks dan selektivitas dengan menggunakan persamaan :

$$
\mathbf{J}=\frac{1}{A} \times \mathbf{d m} / \mathbf{d t}
$$

Keterangan:

$\begin{aligned} \mathrm{J} & =\text { nilai fluks }\left(\mathrm{kg} / \mathrm{m}^{2} \mathrm{jam}\right) ; \\ \mathrm{A} & =\text { luas membran }\left(\mathrm{m}^{2}\right) ; \text { dan } \\ \mathrm{dm} / \mathrm{dt} & =\text { slope grafik antara waktu permeasi dengan } \\ & \text { massa permeat }\end{aligned}$

$$
\alpha=\frac{\left(\mathrm{Y}_{\mathrm{W}} / \mathrm{Y}_{\mathrm{A}}\right)}{\left(\mathrm{X}_{\mathrm{W}} / \mathrm{X}_{\mathrm{A}}\right)}
$$

Keterangan:

$\alpha=$ selektivitas pemisahan;

$\mathrm{Y}_{\mathrm{W}}=$ konsentrasi air dalam permeat $(\%)$;

$\mathrm{Y}_{\mathrm{A}}=$ konsentrasi etanol dalam permeat $(\%)$;

$\mathrm{X}_{\mathrm{W}}=$ konsentrasi air dalam umpan $(\%)$;

$\mathrm{X}_{\mathrm{A}}=$ konsentrasi etanol dalam umpan (\%)

(Okumus et al., 2003).

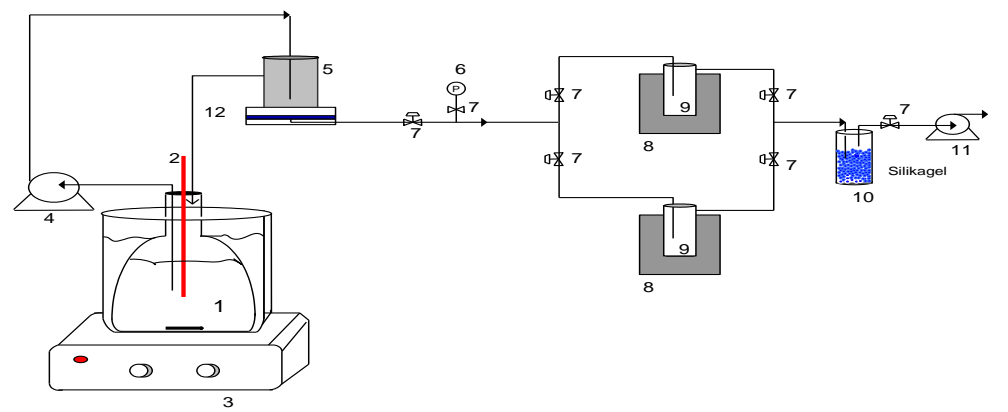

Gambar 1. Rangkaian sel pervaporasi, (1) Labu tempat umpan, (2) Termometer, (3) Pemanas, (4) Pompa sirkulasi, (5) Modul pervaporasi, (6) Pirani gauge, (7) Kran, (8) Tabung dewar, (9) Cold trap, (10) Tabung silika gel, (11) Pompa vakum, (12) Membran 


\section{HASIL DAN PEMBAHASAN}

Hasil penelitian ini menunjukkan adanya pengaruh bahan aditif zeolit dalam membran selulosa asetat terhadap kinerja membran. Pada Gambar 2 menunjukkan bahwa derajat penggembungan membran selulosa asetat 20\% menurun dengan bertambahnya konsentrasi zeolit $(5-20 \% \mathrm{~b} / \mathrm{b})$.

Hal ini disebabkan partikel-partikel zeolit dapat mengisi volume bebas dan tersebar pada matriks membran, dan menyebabkan permukaan membran menjadi lebih rapat. Pernyataan ini dapat ditunjang dengan hasil SEM (Gambar 3) menunjukkan bahwa zeolit menyebar secara homogen pada permukaan membran dan menyebabkan pori membran semakin rapat sehingga derajat penggembungan menjadi turun.

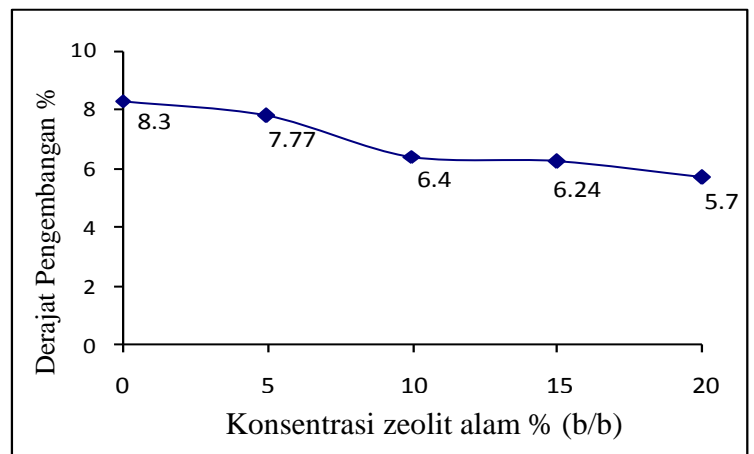

Gambar 2. Derajat penggembungan sebagai fungsi konsentrasi zeolit alam dari membran selulosa asetat $20 \%$ (b/b)
Membran ini selanjutnya diaplikasikan untuk proses pervaporasi yang mensyaratkan penggunaan membran yang rapat dengan derajat penggembungan membran yang relatif kecil (Okumus et al., 2003). Penggembungan membran untuk proses pervaporasi memang diperlukan, namun penggembungan yang berlebihan dapat menyebabkan menurunnya kinerja membran.

Kinerja membran selulosa asetat yang diamati dari proses pervaporasi adalah fluks dan selektivitas. Hasil pengukuran fluks dan selektivitas membran selulosa asetat $20 \%$ dengan variasi konsentrasi zeolit (5-20\% b/b) ditunjukkan pada Gambar 4.

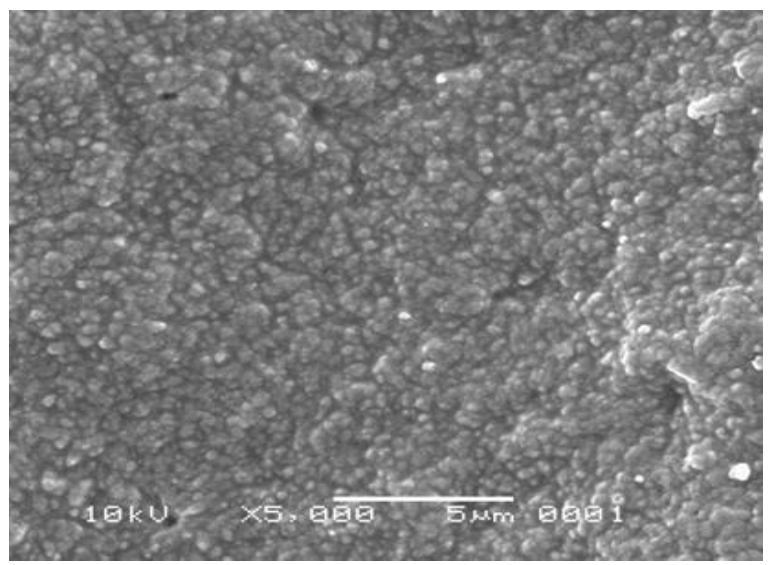

Gambar 3. Gambar hasil SEM, tampak permukaan membran selulosa asetat $20 \%(\mathrm{~b} / \mathrm{b})$ termodifikasi zeolit alam

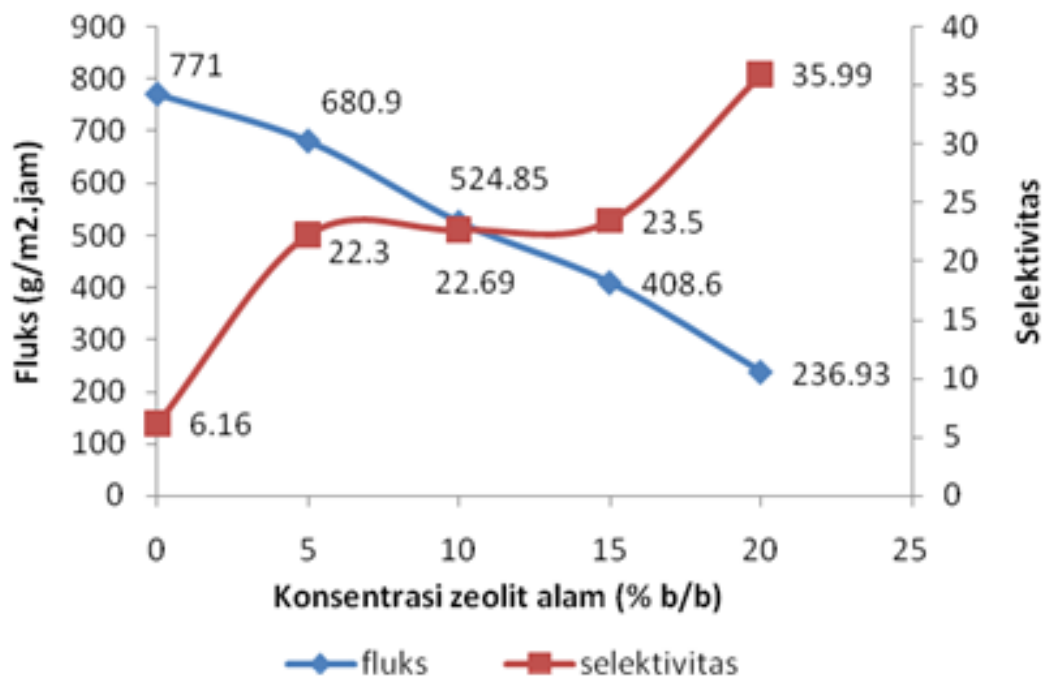

Gambar 4. Fluks dan selektivitas sebagai fungsi konsentrasi zeolit alam dari membran selulosa asetat $20 \%(\mathrm{~b} / \mathrm{b})$

Terlihat penurunan permeat dari $771,0 \mathrm{~g} / \mathrm{m}^{2} \mathrm{jam}$ (membran homogen) menjadi $680,9 \mathrm{~g} / \mathrm{m}^{2}$ jam pada membran selulosa asetat dengan zeolit alam 5\%. Sebaliknya nilai selektivitas mengalami peningkatan yang cukup signifikan yaitu hampir empat kali lipat (6,16 menjadi 22,30$)$. Hal yang sama juga terjadi pada konsentrasi zeolit alam 10,15 , dan $20 \%$, yaitu mengalami penurunan fluks permeat disertai peningkatan selektivitas. Fluks menurun disebabkan berkurangnya laju alir permeat dengan adanya zeolit yang menempati matriks membran dan mengisi volume bebas membran, hal yang sama dikemukakan oleh Bowen et al. (2004). Selektivitas paling tinggi terjadi pada membran selulosa asetat dengan zeolit 
alam $20 \%$, tetapi fluks permeatnya sangat rendah. Hal ini disebabkan pori membran semakin rapat dan derajat penggembungan yang semakin kecil. Sehingga membran dengan komposisi tersebut kurang efektif digunakan untuk proses pemisahan.

\section{KESIMPULAN}

Penambahan zeolit alam dalam membran selulosa asetat dapat meningkatkan selektivitas pemisahan. Komposisi membran selulosa asetat termodifikasi zeolit alam yang terbaik adalah selulosa asetat 20\%-zeolit alam 5\% dengan nilai selektivitas 22,30 dan fluks $680,9 \mathrm{~g} / \mathrm{m}^{2}$ jam sementara selektivitas membran selulosa asetat $20 \%$ tanpa modifikasi adalah 6,16 dan fluks $771,0 \mathrm{~g} / \mathrm{m}^{2} \mathrm{jam}$.

\section{UCAPAN TERIMAKASIH}

Terimakasih disampaikan pada Teja Kistanto, Jurusan Kimia, Fakultas Matematika dan Ilmu Pengetahuan Alam, Universitas Padjadjaran yang telah membantu dalam penelitian ini.

\section{DAFTAR PUSTAKA}

Bowen, T. C., Noble, R. D. \& Falconer, J. L. (2004). Fundamentals and applications of ervaporation through zeolite membranes. Journal of Membrane Science, 245, 1-33.

Goossens, I. \& Van Haute, A. (1976). The influence of mineral fillers on the membrane properties of high flux asymmetric cellulose acetate reverse osmosis membranes. Desalination, 18, 203-214.

Groot, W. J., M.van der Lans, R. G. J. \& Luyben, K. Ch. A. M. (1992). Technologies for butanol recovery integrated with fermentations. Process Biochemistry, 27, 61-72.
Kariduraganavar, M. Y., Kittur, A. A., Kulkarni, S. S. \& Ramesh, K. (2004). Development of novel pervaporation membranes for the separation of water-isopropanol mixtures using sodium alginate and $\mathrm{NaY}$ zeolite. Journal of Membran Science, 238, 165-175.

Kataoka, T., Toshinori, T., Shin-Ichi, N. \& Shoji, K. (1991). Membrane transport properties of pervaporation and vapor permeation in ethanolwater system using polyacrylonitrile and cellulose acetate membranes. Journal of Chemical Engineering of Japan, 24(3), 334-339.

Kittur, A. A., Kariduraganavar, M. Y., Toti, U.S., Ramesh, K. \& Aminabhavi, T.M. (2003). Pervaporation separation of water-isopropanol mixtures using ZSM-5 Zeolite incorporated Poly (Vinyl Alcohol) membranes. Journal of Applied Polymer Science, 90, 2441-2448.

Ma, X., C. Hu, Guo, R., Fang, X., Wu, H. \& Jiang, Z. (2007). HZSM5-filled cellulose acetate membranes for pervaporation of methanol/ mtbe mixtures. Separation Purification Technology, 59, 34-42.

Okumus, E., Turker, G., Levent, Y. (2003). Effect of fabrication and process parameters on the morphology and performance of a PAN-Based zeolite-filled pervaporation membrane. Journal of Membrane Science, 223, 23-38.

Yujun, W., Yang, L., Luo, G. \& Dai, Y. (2009). Preparation of cellulose acetate membrane filled with metal oxide particles for the pervaporation separation of methanol/methyl tert-butyl ether mixtures. Chemical Engineering Journal, 146, 6-10. 